\title{
PENGELOLAAN LABORATORIUM DAN PENGETAHUAN GURU IPA DALAM MEMBUAT MODUL PRAKTIKUM DI SMP TAMAN SASTRA JIMBARAN
}

\author{
G. N. Sutapa ${ }^{1}$, N. N. Ratini ${ }^{2}$, I. M. Yuliara ${ }^{3}$, I. G. A. Kasmawan ${ }^{4}$
}

\begin{abstract}
ABSTRAK
Hasil identifikasi keberadaan tenaga laboratorium IPA di SMP Taman Sastra Jimbaran Kuta Selatan, Badung adalah sekolah swasta yang menunjukkan bahwa umumnya kualifikasi pendidikan tenaga yang ditugaskan di laboratorium IPA belum memenuhi persyaratan standar tenaga laboratorium sekolah. Data yang diperoleh dari interview dengan guru IPA di SMP Taman Sastra Jimbaran, menyatakan bahwa sebagian besar guru IPA masih mengalami masalah untuk melakukan praktikum tentang topik-topik tertentu, tidak semua konsep-konsep IPA eksperimental dapat diajarkan dengan praktikum karena keterbatasan alat-alat dan bahan yang tersedia. Salah satu kendala yang menghambat kelancaran pelaksanaan pembelajaran IPA di laboratorium adalah terbatasnya jumlah dan/atau jenis alat yang tersedia dan belum memiliki petunjuk praktikum yang tersusun secara permanen (dalam bentuk Modul). Hasil pengabdian ini telah mengasilkan beberapa alat praktikum sederhana dan dilengkapi dengan modul praktikum yang telah tersusun dengan baik. Diakhir kegiatan alat praktikum dan modul prkatikum diserahkan kepada SMP Taman Sastra Jimbaran.
\end{abstract}

Kata kunci : Laboratorium, alat praktikum, modul praktikum

\begin{abstract}
The results of the identification of the existence of science laboratory personnel at Jimbaran Taman Selatan Literature Middle School in South Kuta, Badung are private schools that show that generally, the educational qualifications of personnel assigned to the science laboratory have not met the standard requirements of school laboratories. Data obtained from interviews with science teachers at Taman Sastra Jimbaran Middle School stated that most of the natural science teachers still had problems doing practicum on certain topics, not all experimental science concepts could be taught with practicum because of limited tools and materials which is available. One obstacle that hinders the smooth implementation of science learning in the laboratory is the limited number and / or types of tools available and do not have practicum instructions that are permanently arranged (in the form of modules). The results of this dedication have resulted in several simple practicum tools and are equipped with practicum modules that have been well arranged. At the end of the practicum tools and practicum modules, they were handed over to Taman Sastra Jimbaran Middle School.
\end{abstract}

Keywords: Laboratory, practicum tools, practicum modules

\footnotetext{
${ }^{1}$ Program Studi Fisika Fakultas MIPA Universitas Udayana, sutapafis97@unud.ac.id.

${ }^{2}$ Program Studi Fisika Fakultas MIPA Universitas Udayana, nnratini@unud.ac.id

${ }^{3}$ Program Studi Fisika Fakultas MIPA Universitas Udayana imdyuliara@unud.ac.id

${ }^{4}$ Program Studi Fisika Fakultas MIPA Universitas Udayana igdanthakasmawan@ unud.ac.id
} 


\section{PENDAHULUAN}

Hasil identifikasi keberadaan tenaga laboratorium IPA di SMP Taman Sastra Jimbaran Kuta Selatan, Badung adalah sekolah swasta yang menunjukkan bahwa umumnya kualifikasi pendidikan tenaga yang ditugaskan di laboratorium IPA belum memenuhi persyaratan standar tenaga laboratorium sekolah. Para guru IPA yang ditugaskan sebagai pengelola laboratorium maupun staf yang ditugaskan sebagai tenaga laboratorium (laboran/teknisi) kurang memperoleh pelatihan keterampilan laboratorium. Di sisi lain, tindakan atau inovasi peningkatan kompetensi tenaga laboratorium sekolah Swasta masih sangat minim. Data yang diperoleh dari interview dengan guru IPA di SMP Taman Sastra Jimbaran, menyatakan bahwa sebagian besar guru IPA masih mengalami masalah untuk melakukan praktikum tentang topik-topik tertentu, tidak semua konsepkonsep IPA eksperimental dapat diajarkan dengan praktikum karena keterbatasan alat-alat dan bahan yang tersedia. Input yang diperoleh dari tenaga laboratorium IPA di SMP Taman Sastra Jimbaran, bahwa frekuensi penggunaan laboratorium IPA, masih rendah. Salah satu kendala yang menghambat kelancaran pelaksanaan pembelajaran IPA di laboratorium adalah terbatasnya jumlah dan/atau jenis alat yang tersedia.

Berdasarkan hasil observasi di beberapa laboratorium SMP diketahui keberadaan laboratorium yang tidak terkelola dengan baik. Alat-alat yang ada banyak yang tidak tertangani dengan baik, tidak terawat, dan tidak dapat difungsikan secara optimal. Disamping karena sudah rusak, spek dan komponen-komponen alat yang ada tidak sesuai dengan objek praktikum dan belum memiliki petunjuk praktikum yang tersusun secara permanen (dalam bentuk Modul) sebagai pegangan guru. Hal ini menunjukkan bahwa pengelolaan, pemanfaatan dan pemberdayaan laboratorium IPA di sekolah apa adanya, atau seadanya. Lagi pula tenaga yang ditugasi di laboratorium belum memiliki keterampilan/keahlian khusus untuk mereparasi, memodifikasi, dan menduplikasi alat. Dengan situasi yang ada di SMP Taman Sastra Jimbaran seperti dipaparkan diatas sangat penting untuk dilakukan pengabdian Pengelolaan Laboratorium dan Pengetahuan Guru IPA dalam Membuat Modul Praktikum di SMP Taman Sastra Jimbaran.

\section{METODE KEGIATAN}

Pelaksanaan kegiatan dilakukan dengan beberapa langkah :

a. Memberikan pemahaman teori IPA dan aplikasinya pada kehidupan nyata kepada guru-guru, siswa-siswi dan staf laboran serta menjelaskan format modul praktikum di SMP Taman Sastra Jimbaran.

b. Memberikan pelatihan pembuatan alat peraga dan alat-alat praktikum sederhana dari bahan bekas yang terdapat dilingkungan sekitar kepada guru IPA di SMP Taman Sastra Jimbaran.

c. Membimbing dan melatih pelaksanaan praktikum dengan mengunakan alat-alat yan telah dihasilkan oleh guru-guru kepada siswa-siswi SMP Taman Sastra Jimbaran. 


\section{G. N. Sutapa , N. N. Ratini , I. M. Yuliara , I. G. A. Kasmawan}

\section{HASIL DAN PEMBAHASAN}

Pelaksanaan kegiatan pengabdian kepada masyarakat, dimana masyarakat pada kegiatan ini adalah Guru, Laboran dan Siswa-siswi SMP Taman Sastra Jimbaran Kuta Selatan Badung. Kegiatan ini diakukan dengan beberapa tahap. Tahap awal dilakukan dengan membuat alat-alat paraga praktikum IPA seperti dapat ditunjukan pada Gambar 1. berikut,
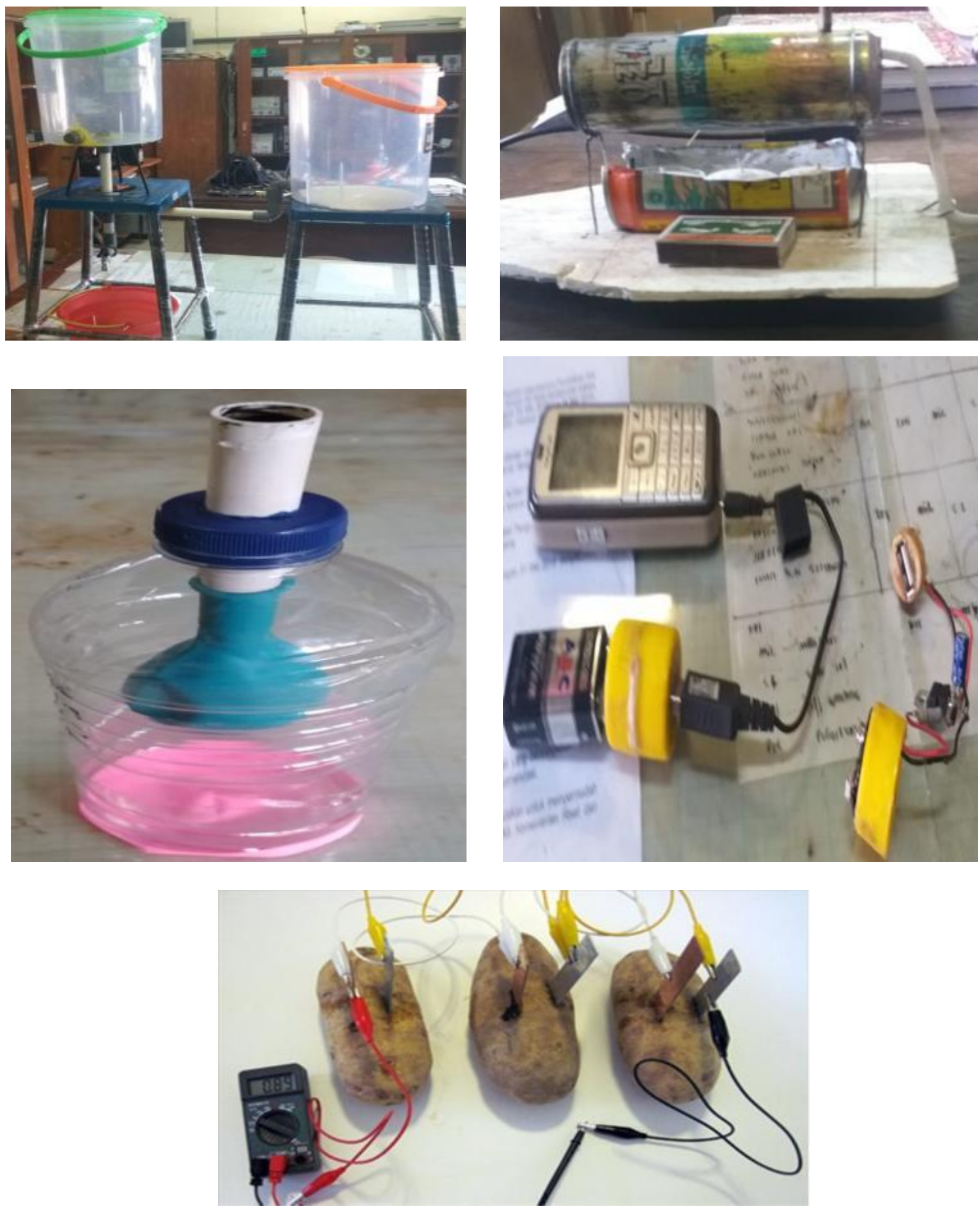

Gambar 1. Beberapa Model Alat Praktikum Sederhana 
Gambar 1. menunjukan beberapa alat-alat peraga praktikum IPA seperti aplikasi perbedaan enegi kenetik dengan energi potensial, kapal uap, pernapasan paru-paru balon, charger Hp dan kentang listrik.

1. Aplikasi Energi Kenetik dan Potensial, proses aplikasi ini menunjukan terjadinya perbedaan gerak akibat tekanan dan posisi dari output air didalam tangki. Percobaan ini dapat dimanfaatkan dalam integrasi air hujan dengan air PDAM,

2. Kapal Uap, kapal dapat bergerak di laut atau di air akibat kaleng yang berisi air dipanaskan dengan lilin hingga mendidih/menguap.

3. Paru-paru Balon, pada saat pipet ditiup atau dimasukan udara, maka balon kecil yang terdapat didalam kaleng akan kembang-kempis sesuai gerakan pernafasan pada paru-paru yang sebenarnya.

4. Charger Hp, kulit pisang yang telah kering dimasukan kedalam batrai bekas yang sebelumnya telah di kosongkan, ternyata kulit pisang dapat menganti batrai yang dapat dimanfaatkan sebagai charcer Hp.

5. Listrik Kentang, umbi kentang dapat sebagai sumber tegangan. Untuk mendapatkan sumber tegangan tinggi dapat dilakukan menyusun kentang secara seri, pararel maupun secara gabungan seri pararel.

Setelah semua peralatan lengkap maka dilanjutkan kelangkah berikutnya. Pada langkah kegiatan ini dilakukan sosialisasi langsung di Sekolah SMP Taman Sastra Jimbaran yang dihadiri oleh siswa-siswi, Guru IPA dan tenaga Laboratorium. Sosialisasi dilakukan untuk memberikan motivasi kepada siswa-siswi SMP dalam memahami pelajaran IPA serta dapat menarik minat siswa-siswi untuk melakukan penerapan terhadap teori yang dipelajari terhadap kehidupan sehari-hari. Pelaksanaan kegiatan selanjutnya adalah melakukan uji coba terhadap alat-alat paraga, yang secara langsung dapat diamati dan dipraktekan oleh siswa-siswi SMP Taman Sastra.

Hasil pelaksanaan kegiatan ini menunjukan kreativitas siswa-siswi untuk mencoba serta melakukan respon dalam bentuk tanyajawab. Respon yang diberikan merupakan bagian yang menarik dari alat-alat peraga IPA ini yang sederhana, mudah dipahami, mudah dilaksanakan dan sangat mermanfaat pada kehidupan nyata. Semua kegiatan sosialisasi dan pelatihan terangkum pada foto-foto kegiatan yang ditunjukan pada Gambar 2 berikut, 

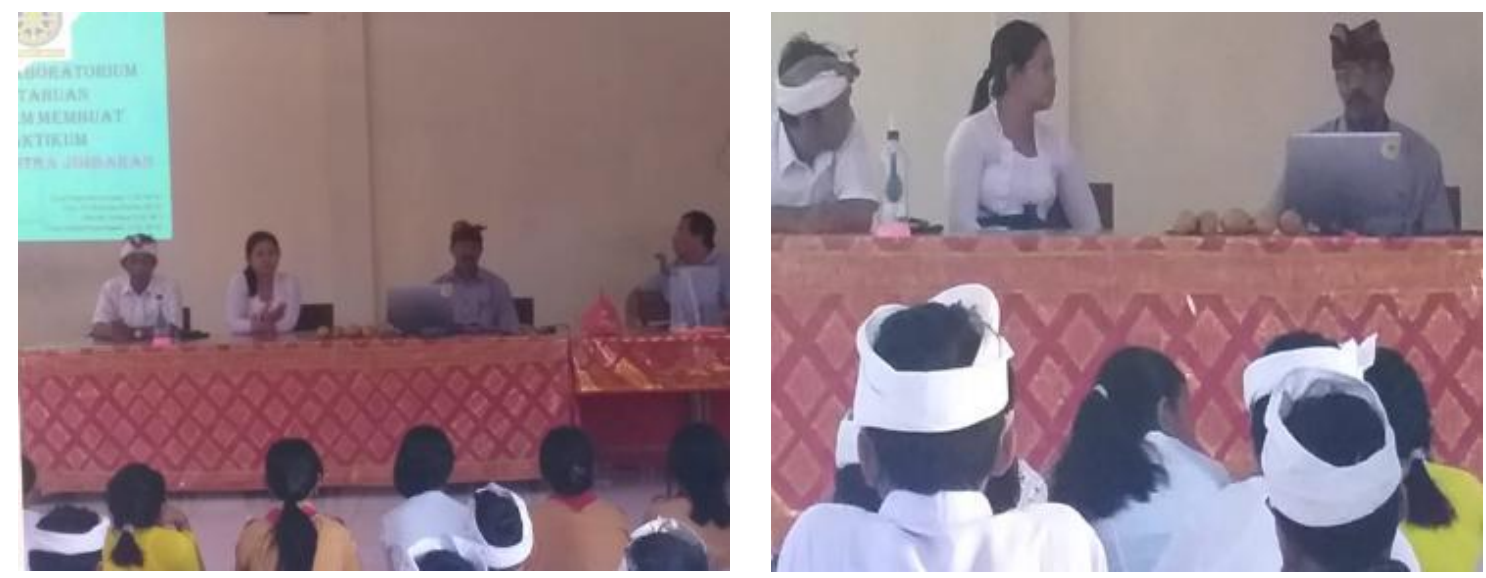

Gambar 2 A. Foto Pelaksanaan Sosialisasi
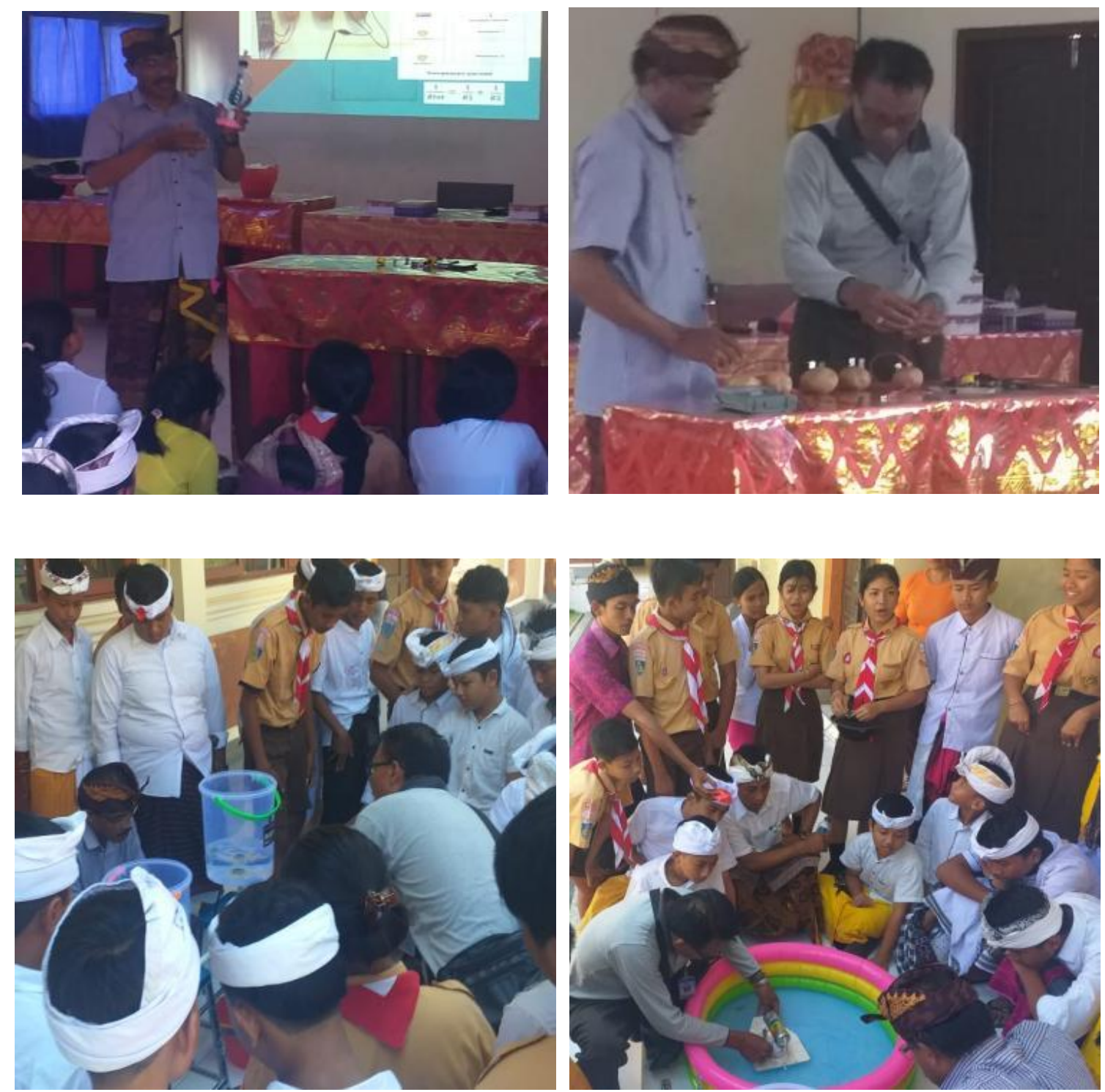

Gambar 2 B. Foto Pelaksanaan Uji Coba Alat 


\section{KESIMPULAN}

Setelah semua kegiatan pengabdian masyaratkat ini dilakukan maka dapat diambil kesimpulan bahwa pelaksanaan pembelajaran IPA perlu dilakukan secara kontinyu dengan bentuk aplikasinya langsung. Salah satu aplikasi yang dapat dilakukan dengan alat-alat peraga IPA sederhana dan dilengkapi modul praktikum.

\section{UCAPAN TERIMA KASIH}

Ucapan terima kasih kepada Universitas Udayana yang telah membiayai pelaksanaan penelitian ini melalui DIPA PNBP tahun anggaran 2019 sesuai dengan Surat Perjanjian Penugasan Pelaksanaan Pengabdian Nomor ; 552-36/UN14.4.A/PM/2019.

\section{DAFTAR PUSTAKA}

Fandi. A dan Muliatna. I.M., 2013, Pengembangan Modul Sistem Penerangan Mobil Matakuliah Praktikum Kelistrikan Otomotif untuk Meningkatkan Efektifitas Belajar di Jurusan Teknik Mesin FT-Unesa, Jurnal Pendidikan Teknik Mesin, Vol. 1 No. 2 p. 93-99.

Kistiono dan Suhandi, A., 2013. Pengembangan Model Praktikum Berbasis Fenomena Alam untuk Meningkatkan Pemahaman Konsep Mahasiswa Calon Guru Fisika, Prosiding Seminar Biologi, Vol.10 No. 1. 3-028.

Khasani, Soeinanto Imam. 2001. Material Safety Data Sheet (MSDS). Vol III. Bandung: Pusat Penelitian IPA Lembaga Ilmu Pengetahuan Indonesia

Riri J., Yurnetti, Hidayati, dan Fatni M., 2014, Efektivitas Pengetahuan Pengelolaan Laboratorium dan Substansi Bahan Ajar terhadap Pengetahuan Guru Membuat Modul Praktikum IPA SMP dalam Menyambut Kurikulum 2013, Jurnal Penelitian Pendidikan, Volume 5, No. 1, Januari 2014.

Subamia dan Wiratini. 2008. Penataan, Penyimpanan dan Perawatan Alat dan Bahan $(P 3 A B)$ di Laboratorium IPA. Modul Pelatihan Manajemen Laboratorium bagi Guru dan laboran SMA se Bali,

Subamia I. D. P. 2011. Penelusuran Kinerja Laboratorium IPA SMP. Laporan Studi Pendahuluan Analis Kebutuhan pada Pengelolaan Laboratorium IPA SMP di Kabupaten Buleleng. 